\title{
TAPES-G: A GRID-BASED TERRAIN ANALYSIS PROGRAM FOR THE ENVIRONMENTAL SCIENCES
}

\author{
JOHN C. GALLANT ${ }^{1}$ and JOHN P. WILSON ${ }^{2}$ \\ ${ }^{1}$ Centre for Resource and Environmental Studies, Institute of Advanced Studies, Australian National \\ University, Canberra ACT 0200, Australia (e-mail: johng@cres.anu.edu.au) and ${ }^{2}$ Department of Earth \\ Sciences, Montana State University, Bozeman MT 59717-0348, U.S.A.
}

(Received 15 December 1994; revised 10 January 1996)

\begin{abstract}
TAPES-G is a grid-based terrain analysis program that computes slope, aspect, upslope contributing area, profile and plan curvature and several other topographic attributes for each cell of a square-grid digital elevation model (DEM). These topographic attributes can be used to represent key physical processes in a form simple enough to allow modeling at catchment and larger scales. The program creates initially a depressionless DEM if desired. Upslope contributing area can be calculated using either the classical D8 algorithm, the quasi-random Rho8 algorithm, the multiple flow direction FD8/FRho8 algorithm or Costa-Cabral and Burges's stream tube-based DEMON algorithm. Stream networks, sub-catchments and the spatial distribution of individual attributes can be plotted interactively or copied to the ARC/INFO geographic information system (GIS) for further processing. Copyright $\bigcirc 1996$ Elsevier Science Ltd.
\end{abstract}

Key Words: DEM, Terrain analysis, Topographic attributes.

\section{INTRODUCTION}

Topography plays an important role in the hydrological response of a catchment to rainfall and has a major impact on the hydrological, geomorphological and biological processes that are active in landscapes (Moore, Grayson, and Ladson, 1991). The increasing availability of digital elevation models (DEMs) and advent of computerized terrain analysis tools has made it possible to quantify the topographic attributes of a landscape. These attributes can be divided into primary and secondary (or compound) attributes. Primary attributes are calculated directly from a DEM and include slope, aspect, profile and plan curvature, flow path-length and specific catchment area. Dikau (1989), for example, used slope, plan curvaturc and profile curvature to delineate geomorphological relief units and Moore, Grayson, and Ladson (1991) generated a table describing seventeen different primary topographic attributes and their hydrological significance. Compound attributes involve combinations of two or more primary attributes and can be used to characterize the spatial variability of specific processes occurring in the landscape. Moore and others (1993c) used a steady-state wetness index to characterize the spatial distribution of zones of surface saturation and soil water content, and a sediment transport index to characterize erosion and deposition processes across landscapes. Both of these compound indices incorporated slope, which is an approximate measure of the hydraulic grade and the rate of dissipation of potential energy in surface and subsurface flow, and specific catchment area, which is an approximate measure of runoff per unit width and convergence and divergence of flow.

This paper describes TAPES-G, an acronym for terrain analysis programs for the environmental sciences-grid version. This program was developed by Professor Ian Moore, and the authors have taken responsibility for developing, publicizing and distributing this and other programs since his death in 1993. TAPES-G generates primary topographic attributes from a DEM, and other programs such as EROS (Wilson and Gallant, 1996a) and WET (Gallant and Wilson, 1996) use these to derive secondary attributes. The focus of Professor Moore's terrain analysis work was to develop simple, physically-based models of key environmental processes based on readily available data so that spatial patterns in those processes could be studied readily. Other papers have presented some of the algorithms and applications of TAPES-G (Moore, Norton, and Williams, 1993; Moore and others, 1993a; Moore and others, 1993b; Moore and Wilson, 1992; Moore, Lewis, and Gallant, 1993), and the aims of this paper are to present enough information to allow a potential user of the program to assess the usefulness of TAPES-G for their application, and to describe the program in sufficient detail that users will have little difficulty obtaining good quality terrain analysis results. The input data, computed terrain attributes and options and parameters that can be specified by the user when running the program are discussed. 
TAPES-G is written in FORTRAN-77 and $C$ for Unix platforms and includes tools for displaying results in color using $X$ Windows, statistical analysis and fitting frequency distributions to the results.

\section{GRID TERMINOLOGY}

It is important at the outset to clarify the difference between grid cells and grid points. A grid cell is a small square region generally oriented with sides in the $\mathrm{N}-\mathrm{S}$ and $\mathrm{E}-\mathrm{W}$ directions, referenced by a single coordinate pair which represents usually either the SW (bottom left) corner or the center of the cell. It has a fixed area which is the square of the grid spacing. A grid point is a mathematical point with no area. In ARC/INFO parlance a grid cell is an element of a grid coverage and a grid point is an element of a lattice coverage.

In TAPES-G it is best to think of the computed attributes as grid point values rather than grid cell values, although the results are displayed usually as grid cells with finite area (at least one pixel). The computations in TAPES-G use finite difference approximations to derivatives to compute slope, aspect and curvature at each DEM point so these attributes are point values and not averages over cells. Upslope contributing area, in contrast, must be considered as a cell value rather than a point value, and the contributing area algorithms all compute the area leaving a grid cell. The flow width (or contour length) needed for computing specific catchment area is assumed to be the distance across the cell orthogonal to the flow direction.

\section{TAPES-G INPUTS}

TAPES-G can accept DEM files in several different formats. The DEM can be either $x, y, z$ triplets or just $z$ (elevation) values. An $x, y, z$ file can have points in any order, while a $z$-only file may be in either row or column order with the first point in either the NW or SW corner. $z$ values may be either integer or floating point; if they are integer values a scaling factor may be applied, which is often used to increase the vertical resolution. Finally, the file may be in either ASCII or binary form.

ASCII files have one record per line. Unformatted binary files (integer or floating point) also are record oriented, with each record preceded and followed by a four-byte integer specifying the number of bytes in the record (standard FORTRAN unformatted records). Files containing $x, y, z$ triplets must have one triplet per record, while files containing only $z$ values may have any number of $z$ values per record, so long as each new column or row starts in a new record. One row or column per record is the usual format. Direct access two-byte integer files containing only $z$ values are accepted also.

An input elevation value of 0 indicates a missing value or point outside the analysis region. TAPES-G will not compute attributes for points with 0 elevation, and all elevations for the region to be analyzed should be positive. TAPES-G also assumes that coordinates and elevation values are in meters, but other units may be used provided that elevation is in the same units as the $X$ and $Y$ coordinates.

Some additional processing may be required to create a square-grid DEM prior to running TAPESG. We use ANUDEM (Hutchinson, 1989) for this purpose. This program takes irregular point data (e.g. a 3 arc-sec USGS DEM or a GPS $x, y, z$ data set) or contour data (a digital line graph file, for example) and creates square-grid DEMs. ANUDEM automatically removes spurious pits within user-defined tolerances, calculates stream and ridge lines from points of locally maximum curvature on contour lines, and (most importantly) incorporates a drainage enforcement algorithm that maintains fidelity with a catchment's drainage network. ANUDEM is included in ARC/INFO (Release 7.0 and higher) as the TOPOGRID command, or it can be obtained as a self-contained program from the Centre for Resource and Environmental Studies at the Australian National University. The TAPES-G user also must make sure the DEM fits into the size limits set when the program is compiled. The arrays are set currently to 1000 rows and 1000 columns, although the user can change these values to suit the memory space of their machine and the size of their study area (DEM). The numbers of rows and columns do not have to be equal. The memory requirements are approximately 80 bytes per grid cell (thus requiring 80 Mbytes of virtual memory in the standard configuration) or 40 bytes per grid cell if the program is compiled without the DEMON module.

\section{TAPES-G OUTPUTS}

TAPES-G produces an output attributes file in either binary or ASCII format. The fourteen primary topographic attributes that are written to this file are summarized in Table 1. Each DEM grid point with all its attributes is written as a single record - either one line in an ASCII file or one unformatted record in a binary file. The user can select whether to write records for points with missing (0) elevation data. Such records contain no-data values for all attributes other than $X$ and $Y$. The no-data value $(-999.0)$ is used also where an attribute is undefined, such as for aspect when the surface is perfectly flat. Other programs using the output of TAPES-G must be aware of the no-data value and take appropriate action when it is encountered.

In addition to the computed terrain attributes, metadata is written to the beginning of the file, describing the contents of the file and the options and parameters used by TAPES-G to produce the file. This metadata is used by other programs (such as WET and EROS) to locate the attributes they require, and by TAPESOUT which reformats the 
Table 1. TAPES-G output fields

\begin{tabular}{|c|c|c|}
\hline Attributes & Units & Definitions and notes \\
\hline$X, Y$ & Usually meters & $\begin{array}{l}X \text { and } Y \text { coordinates as specified in input file or deter- } \\
\text { mined from the } X \text { and } Y \text { limits entered by the user. }\end{array}$ \\
\hline Flow direction & $\begin{array}{l}\text { Flow numbering convention } \\
\text { of Figure IB }\end{array}$ & As computed by D8 or Rho8 algorithms. \\
\hline$Z$ & Usually meters & Elevation as read from DEM file. \\
\hline Upslopc contributing arca & $\begin{array}{l}\text { Number of cells or square } \\
\text { meters }\end{array}$ & Arca draining out of each cell. \\
\hline Flow width & Cells & Required to compute specific catchment areas. \\
\hline Slope & Percent & $\begin{array}{l}\text { The slope angle is arctan(slope } / 100) \text {. Note that slope can } \\
\text { exceed } 100 \% \text { in steep areas, since } 100 \% \text { corresponds } \\
\text { to a } 45^{\circ} \text { slope. }\end{array}$ \\
\hline Aspect & Degrees clockwise from north & $\begin{array}{l}\text { The direction of steepest downwards slope. The angle is } \\
\text { a compass bearing. }\end{array}$ \\
\hline Profile curvature & $1 /(100$ meters $)$ & $\begin{array}{l}\text { Curvature of the surface in the direction of maximum } \\
\text { downwards slope. }\end{array}$ \\
\hline Plan curvature & $1 /(100$ meters $)$ & Curvature of contour drawn through the grid point. \\
\hline Tangential curvature & $1 /(100$ meters $)$ & $\begin{array}{l}\text { Curvature of line formed by intersection of surface with } \\
\text { plane normal to flow line. }\end{array}$ \\
\hline Elevation residual & Usually meters & $\begin{array}{l}\text { Difference between original DFM and the depressionless } \\
\text { DEM created during TAPES-G processing. }\end{array}$ \\
\hline Flow path length & Usually meters & $\begin{array}{l}\text { The longest flow path from catchment divide or edge of } \\
\text { DEM to the cell. }\end{array}$ \\
\hline $\mathrm{d}(A s) / \mathrm{d} s$ & Unitless (meters/meter) & $\begin{array}{l}\text { Rate of change of specific catchment area } a \text { along a flow } \\
\text { line. Used for erosion models. }\end{array}$ \\
\hline
\end{tabular}

output data to the form required by ARC/INFO's ASCIIGRID command, permitting visualization and further analysis within the ARC/INFO GIS.

\section{ESTIMATION METHOD}

Most of the Lopographic attributes listed in Table 1 are determined locally from the derivatives of the topographic surface. These derivatives are estimated using centered finite differences

$$
\begin{aligned}
& z_{x}=\frac{\partial z}{\partial x} \simeq \frac{z_{2}-z_{6}}{2 h} \\
& z_{y}=\frac{\partial z}{\partial y} \simeq \frac{z_{8}-z_{4}}{2 h} \\
& z_{x x}=\frac{\partial^{2} z}{\partial x^{2}} \simeq \frac{z_{2}-2 z_{9}+z_{6}}{h^{2}} \\
& z_{y y}=\frac{\partial^{2} z}{\partial y^{2}} \simeq \frac{z_{8}-2 z_{9}+z_{4}}{h^{2}} \\
& z_{x y}=\frac{\partial^{2} z}{\partial x \partial y} \simeq \frac{z_{7}-z_{1}-z_{5}+z_{3}}{4 h^{2}}
\end{aligned}
$$

and two other quantities also appear frequently.

$$
\begin{aligned}
& p=z_{r}^{2}+z_{r}^{2} \\
& q=p+1 .
\end{aligned}
$$

Figure 1A shows the arrangement of the nine grid points which enter into the finite-difference equations, and $h$ is the grid spacing of the DEM. At the edge of

the DEM, forward and backward difference schemes are used.

\section{Slope}

The maximum slope as a ratio can be computed from the finite differences

$$
s_{\mathrm{FD}}=p^{1 / 2} \text {. }
$$

A simpler approximate approach (D8 approach) calculates the gradient as the steepest slope to one of the eight nearest neighbors

$$
s_{\mathrm{D} 8}=\max _{i=1.8} \frac{z_{9}-z_{i}}{h \phi(i)}
$$

where $\phi(i)=1$ for $\mathrm{E}, \mathrm{S}, \mathrm{W}$ and $\mathrm{N}$ neighbors $(i=2$, 4,6 , and 8 ) and $\phi(i)=\sqrt{2}$ for NE, SE, SW and NW neighbors ( $i=1,3,5$ and 7). Moore, Lewis, and

A

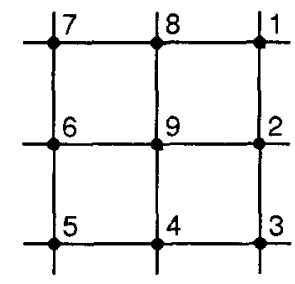

Figure $1.3 \times 3$ sub-grid of grid-based DEM showing (A) node numbering convention, and (B) flow direction numbering convention. 
Gallant (1993) found that the D8 approach predicted slightly larger average slopes than the finite difference approach for a $20 \mathrm{~m} \mathrm{DEM}$ of their Brindabella study site in south-eastern Australia. The D8 algorithm can be useful, particularly when the slope of channels is required, since the slope estimated using finite differences can include steep slopes adjacent to the channel. Using D8 slope guarantees that the slope calculated at a cell corresponds to the slope in the primary flow direction.

Regardless of which estimation method is used, TAPES-G reports slope in percent, or $s \times 100$. Slope angle $\beta$ can be calculated from slope using

$$
\beta=\arctan (s)
$$

remembering first to divide the TAPES-G slope value by 100 .

\section{Aspect and primary flow direction}

Aspect $\psi$ (measured in degrees clockwise from north) can be estimated from the finite differences by

$$
\psi_{\mathrm{FD}}=180-\arctan \left(\frac{z_{y}}{z_{x}}\right)+90\left(\frac{z_{x}}{\left|z_{x}\right|}\right) .
$$

When the slope is less than some minimum value $s_{\text {min }}>0$ the aspect computed from Equation (6) is somewhat arbitrary and the terrain should be classified as flat, with undefined aspect (Mitasova and Hofierka, 1993).

The primary flow direction, FLOWD, is an approximate surrogate for aspect. This is essentially the primary flow direction for water moving over the land surface and identifies the direction to the nearest neighbor with maximum gradient, exactly as in Equation (4)

$$
F L O W D=2^{i-1} \text { where } j=\arg \max _{i=1,8} \frac{z_{9}-z_{i}}{h \phi(i)} .
$$

Aspect is approximated as $\psi_{\mathrm{D} 8}=45 j$. FLOWD is encoded using a binary notation (Fig. 1B) which permits identification of flow to multiple nearest neighbors (although this capability is not actually used in TAPES-G).

If the central node $\left(z_{9}\right)$ is the lowest of the nine it is considered a sink and $F L O W D=0$, unless the option to create a depressionless DEM is invoked. In this case Jenson and Domingue's (1988) algorithm is used to assign flow directions in depressions so that the entire surface is drained. TAPES-G reports the elevation residual between the original elevation and the elevation as modified to fill depressions, which is useful for checking whether the depressions found are substantial enough to warrant a revision of the DEM. The depressionless DEM can be saved for re-use at a later date.

Aspect is useful for visualizing landscapes, especially when using a well-chosen color scale (Kimerling and Moellering, 1989). Aspect, when combined with slope, is useful for modeling exposure to solar radiation, although the SRAD program
(Wilson and Gallant, 1996b) provides a more sophisticated approach for this application.

\section{Curvature}

Surface curvatures can be thought of as the curvature of a line formed by the intersection of a plane and the topographic surface. The curvature of a line is the reciprocal of the radius of curvature, so a gentle curve has a small curvature value and a tight curve large curvature value. The directions of meaningful curvature for hydrological and geomorphological applications are in the direction of maximum slope (profile curvature) and transverse to the slope (plan and tangential curvature). Profile curvature $K_{\mathrm{p}}$ is obtained using a vertical plane aligned with the flow direction (aspect), and is a measure of the rate of change of potential gradient and is important therefore for characterizing changes in flow velocity and sediment transport processes. Plan curvature or contour curvature $K_{c}$ is obtained using a horizontal plane (which forms a contour) and measures the topographic convergence and divergence and hence, the concentration of water in a landscape. Mitasova and Hofierka (1993) propose that tangential curvature is more appropriate than plan curvature for studying flow convergence and divergence. Tangential curvature $K_{t}$ is obtained using a plane normal to the flow path (in three dimensions), and it is related to plan curvature by

$$
K_{\mathrm{t}}=K_{\mathrm{c}} \sin \beta
$$

and the distributions of convex and concave areas derived from plan and tangential curvature are the same.

The usual finite difference formulas for the three curvatures are:

$$
\begin{aligned}
& K_{\mathrm{p}}=\frac{z_{x x} z_{x}^{2}+2 z_{x y} z_{x} z_{y}+z_{y y} z_{y}^{2}}{p^{1 / 2} q^{3 / 2}} \\
& K_{\mathrm{c}}=\frac{z_{x x} z_{y}^{2}-2 z_{x y} z_{x} z_{y}+z_{y y} z_{x}^{2}}{p^{3 / 2}} \\
& K_{\mathrm{t}}=\frac{z_{x x} z_{x}^{2}+2 z_{x y} z_{x} z_{y}+z_{y y} z_{y}^{2}}{p^{1 / 2} q^{3 / 2}} .
\end{aligned}
$$

Using these formulas, profile curvature is negative for slope increasing downhill (convex flow profile, typically on upper slopes) and positive for slope decreasing downhill (concave flow profile, typically on lower slopes). Plan curvature is negative for diverging flow (on ridges) and positive for converging flow (in valleys). In a recent modification to TAPES$G$ an option has been added to reverse these sign conventions to give positive values for convex curvatures, which is a more frequently used sign convention. Curvature values are typically small (nearly always less than 1) so TAPES-G multiplies all curvatures by 100 .

Apart from their use in modcling flow characteristics, curvatures can be used to delineate geomorphic units (Dikau, 1989). Plan curvature can be used to 
differentiate between ridges, valleys and hillslopes, whereas profile curvature can differentiate between upper slopes and lower slopes.

Any errors in a DEM will be enhanced in the computed values of the curvature parameters because these parameters are based on second derivatives. Furthermore, DEMs that have been interpolated primarily from contour data often display biases towards the elevations of the contour data, and profile curvature (in particular) can alternate in sign systematically down a hillslope giving a "wavy" appearance. This result occurs because the density of data is high along the contours, but there are no data between contours. The interpolation methods give more variation in shape (curvature) where the elevation data are densest. In some landscapes this "waviness" is a real phenomenon (Moore, Lewis, and Gallant, 1993).

Upslope contributing area, flow width and specific catchment area

The estimation of both upslope contributing area and specific catchment area (drainage area per unit width orthogonal to a flowline) is dependent on the estimation of flow direction(s) from a given node (node 9 in Fig. 1A). Upslope contributing area is referred to also as drainage area and catchment area. TAPES-G reports contributing area in either number of cells or $\mathrm{m}^{2}$. Four different approaches are available in TAPES-G for calculating contributing areas: D8, Rho8, FD8/FRho8 and DEMON.

The D8 (deterministic eight-node) algorithm developed by O'Callaghan and Mark (1984) allows flow from a node to only one of eight nearest neighbors based on the direction of steepest descent, as defined in Equation (7). This algorithm tends to produce flow in parallel lines along preferred directions which will only agree with the aspect when the aspect is a multiple of $45^{\circ}$, and it cannot model flow dispersion. For example, on a surface with aspects ranging from 0 to 22.5 , the D8 algorithm will predict a constant flow direction $F L O W D=128$ (due north). Even with these significant limitations, the D8 algorithm remains the most frequently used method for determining contributing areas. Figure $2 \mathrm{~A}$ shows upslope contributing area computed using the D8 method on a small catchment ncar Wagga in southeastern Australia (Grayson and Moore, 1992). The $5 \mathrm{~m}$ resolution DEM was derived from contours at $1 \mathrm{~m}$ intervals using ANUDEM (Hutchinson, 1989). Note the parallel flow paths on the slope on the southern side of the main catchment.

The Rho8 (random eight-node) algorithm developed by Fairfield and Leymarie (1991) is a stochastic version of the D8 algorithm in which a degree of randomness is introduced into the flow direction computations, with the aim of breaking up parallel flow paths and giving an expected flow direction equal to the aspect. This is achieved by replacing $\phi(i)$ in Equation (7) by $(2-r)$ for the diagonal neighbors
( $i=1,3,5$ or 7 in Figure 1A), where $r$ is a uniformly distributed random variable between 0 and 1 . Like the D8 algorithm, the Rho8 algorithm cannot model flow dispersion, but it does simulate more realisticlooking flow networks. The breakup of long paralle] flow paths comes at the cost of introducing many more cells without an upslope connection, distorting the distribution of contributing area. The randomizing of flow directions also results in different flow networks each time the program is run, which generally is undesirable. The Rho8 algorithm no longer is considered a useful alternative to D8, but remains as an option in the program. Figure 2B shows contributing area computed on the samc Wagga $5 \mathrm{~m}$ DEM using the Rho8 algorithm. Note that the large uniform areas predicted by $D 8$ have been reduced and in many cases resolved into distinct flow lines.

The FD8 and FRho8 algorithms are modifications of D8 and Rho8 that allow flow dispersion to be represented (Moore and others, 1993c). This pair of algorithms allows flow to be distributed to multiple nearest-neighbor nodes in upland areas above defined channels and uses the D8 or Rho8 algorithms below points of presumed channel initiation. Above channels the proportion of flow or upslope contributing area assigned to each downslope neighbor is determined on a slope-weighted basis as proposed by Freeman (1991), and Quinn and others (1991). The fraction of contributing area passed from a cell to neighbor $i$ is given by

$$
F_{i}=\frac{\max \left(0, s_{i}^{v}\right)}{\sum_{i=1}^{8} \max \left(0, s_{i}^{v}\right)}
$$

where $s_{i}$ is the slope from the central node to neighbor $i$ and $v$ is a positive constant. Freeman (1991) found that $v=1.1$ produced the most accurate results for artificial conical surfaces, and TAPES-G uses that value. Recently Holmgren (1994) reported that much higher values of $v$ in the range $6-8$ could be more appropriate in many landscapes.

The FD8 and FRho8 algorithms give more realistic distributions of contributing area in upslope areas, while also eliminating D8's parallel flow paths. This algorithm tends to cause considerable dispersion of flow in valleys, which generally is considered undesirable because stream lines usually are well defined in valleys. The algorithm is disabled therefore and replaced by $\mathrm{D} 8$ or Rho8 wherever the contributing area exceeds a user-specified threshold, called the "maximum cross grading area" in TAPES-G. The dispersion in valleys can be considered as representing a floodplain or riparian area, and in some applications it may be desirable to set the maximum cross grading area to a very large value so that this dispersion in valleys is modeled. The transition from multiple- to single-flow direction algorithm can cause a bump in the frequency distribution of the contributing area, particularly if the maximum cross grading 


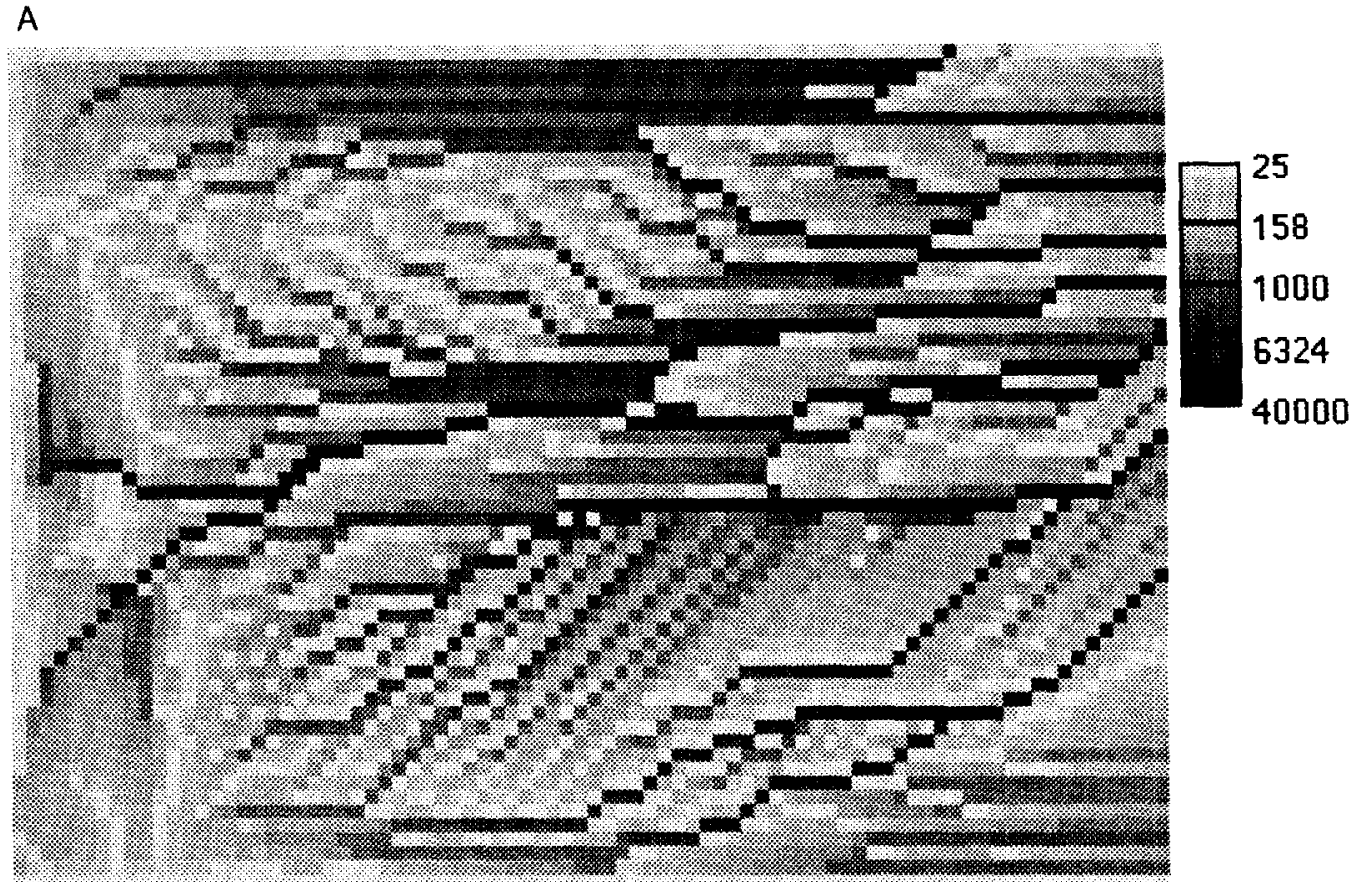

B

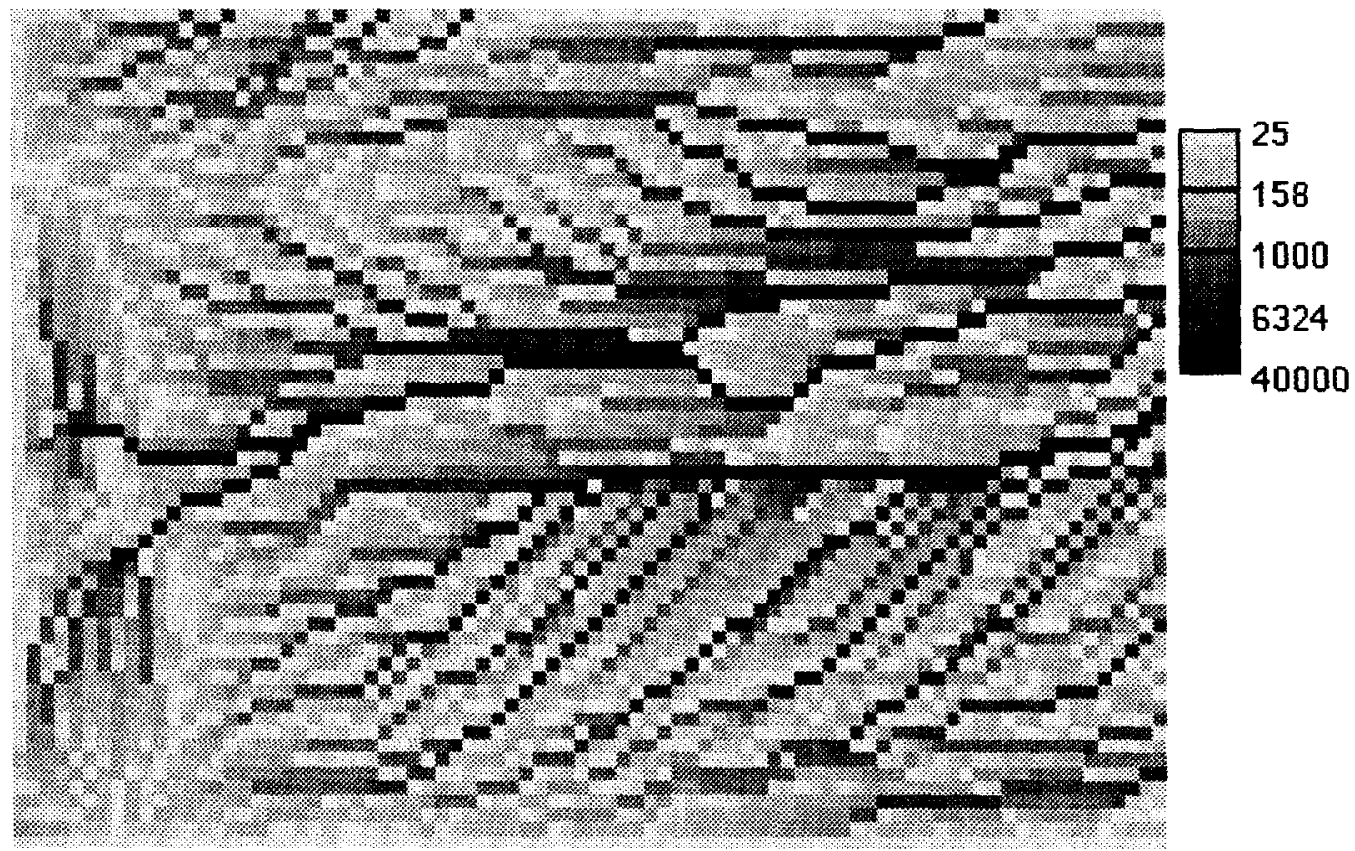

Figure 2(A and B)-Caption opposite.

area is set to too small a value. Depending on the landscape, a maximum cross grading area of about 10 ha or $100,000 \mathrm{~m}^{2}$ is a reasonable starting point. FD8/FRho8 takes considerably longer to run than D8 or Rho 8 because of the greater density of flow connections. Figure $2 \mathrm{C}$ shows the contributing area for the Wagga DEM computed using the FD8 algor- ithm with a large maximum cross grading area so flow dispersion is applied everywhere. Note the smooth variation of contributing area in the upland areas in contrast to the D8 and Rho8 results, and the considerable flow dispersion in the valley areas.

The fourth and final algorithm provides a completely different approach for modeling flow 
C

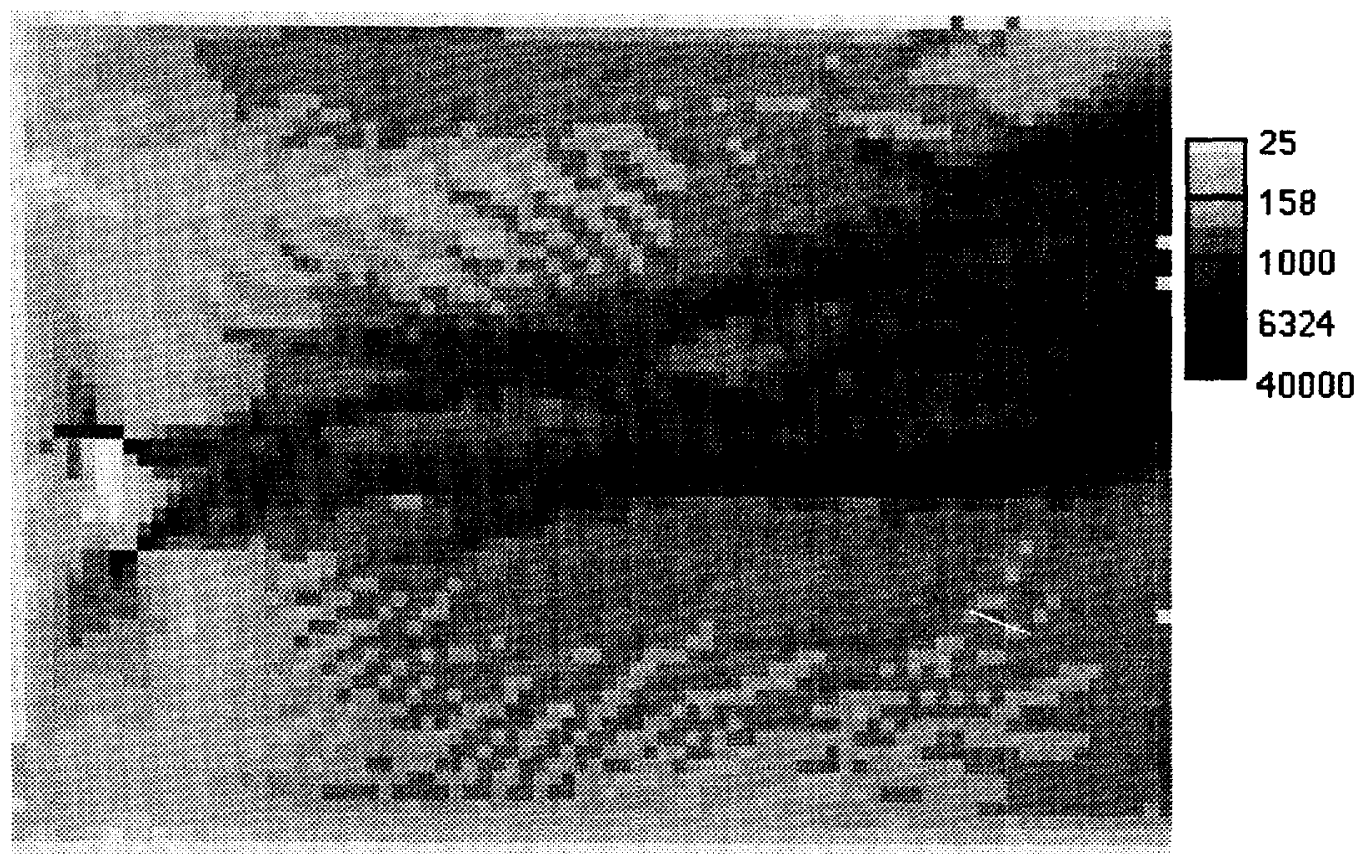

D

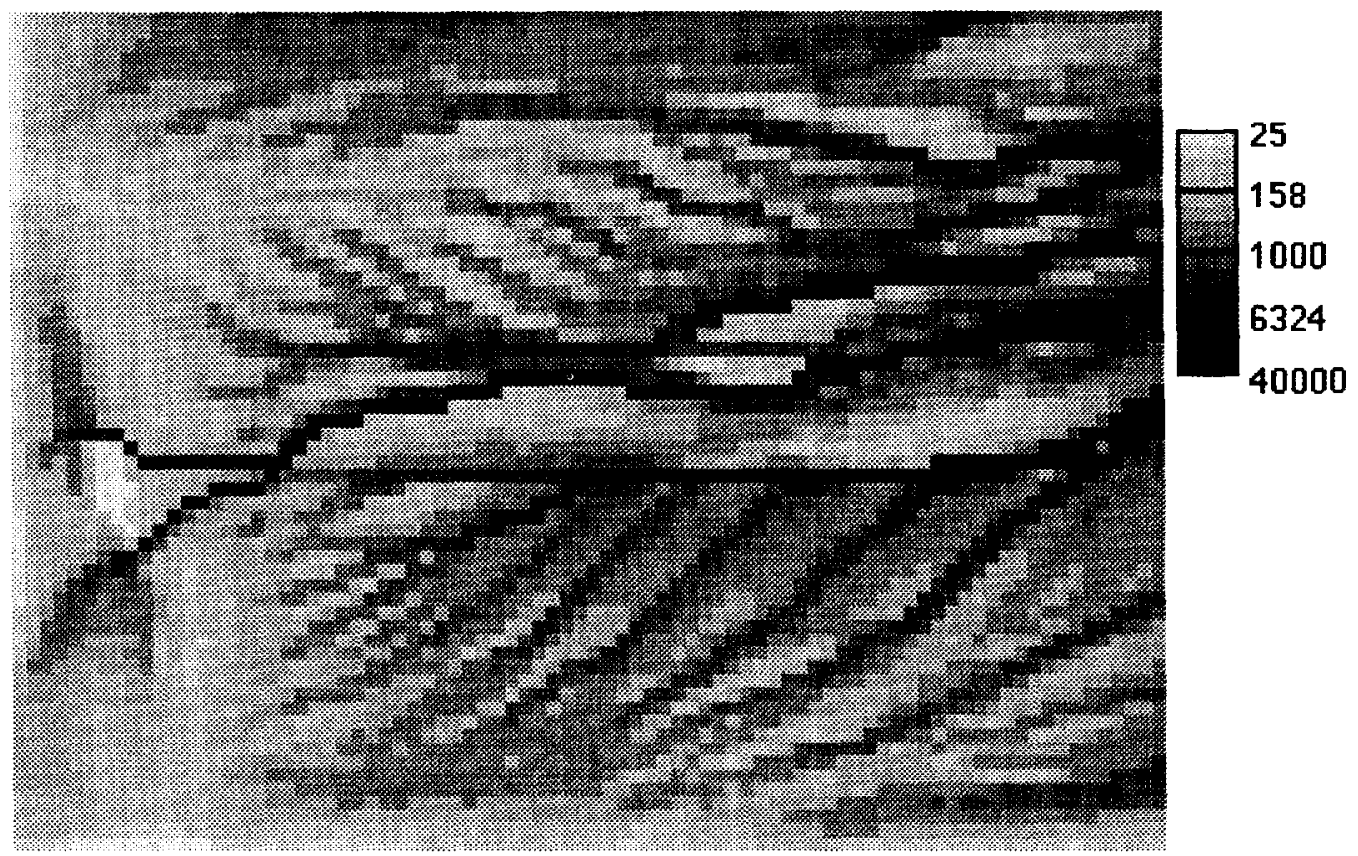

Figure 2(C and D)

Figure 2. Upslope contributing area computed on $5 \mathrm{~m}$ resolution DEM using A. D8 algorithm, B. Rho8 algorithm C. FD8 algorithm, and D. DEMON algorithm. Areas are in $\mathrm{m}^{2}$. North is towards the top of the page.

accumulation and dispersion. This method, which is similar conceptually to the strcam-tube approach used with contour-based DEMs by Moore and Grayson (1991), was proposed first by Lea (1992) and
Costa-Cabral and Burges (1994). Costa-Cabral and Burges's program is called DEMON (digital elevation model network extraction). In DEMON, flow is generated at each pixel (source pixel) and is followed 
down a stream tube until the edge of the DEM or a pit is encountered. The stream tubes are not constrained to the edges of cells and can expand and contract as they traverse divergent and convergent regions of the DEM surface. The stream tubes or flow paths are computed as points of intersections of a line drawn in the gradient direction (aspect) and a grid cell edge. The amount of flow, expressed as a fraction of the area of the source pixel, entering each pixel downstream of the source pixel is added to the flow accumulation value of that pixel. After flow has been generated on all pixels and its impact on each of the pixels has been added, the final flow accumulation value is the total upslope area contributing runoff to each pixel.

The DEMON algorithm has been incorporated into TAPES-G with some modification. In TAPESG, DEMON can be applied to either the original DEM or a derived depressionless DEM; the nodes of the DEM define the centroid of the pixels rather than the vertices; and the flow direction of a stream tube in each pixel is defined by the aspect, calculated using Equation (6). DEMON takes a similar amount of processing time to FD8/FRho 8 and gives results of similar quality. Figure $2 \mathrm{D}$ shows the contributing area computed using the DEMON algorithm. Note the smooth variation of contributing area in the upland areas, similar to FD8, but well-defined channels in the lowlands which are more similar to D8.

Contributing area values can be inaccurate where the edge of the DEM does not coincide with the edge of a catchment unless the flow direction is outwards across the border of the DEM. TAPES-G does not identify cells that are contaminated with edge effects, but it does allow the user to interactively choose drainage basins for analysis instead of analyzing the whole DEM. If requested, TAPES-G will display a flow network highlighting drainage lines with contributing area greater than a user-specified amount, and the user can select (using a point-and-click graphical interface) outlet points which define drainage basins to be analyzed. Drainage boundaries can alternatively be specified using a file containing $X$ and $Y$ coordinates of a bounding polygon defining the region to be analyzed.

TAPES-G computes a flow width attribute $w$ which is used to compute specific catchment area $a$ from contributing area $A$

$$
a=\frac{A}{w} .
$$

Flow width is reported in terms of cell width and is computed in different ways for different flow algorithms. For the D8 and Rho8 algorithms, flow width is equal to cell width for flow in cardinal directions $(i=2,4,6$ and 8$)$ and $\sqrt{2}$ for flow in diagonal directions $(i=1,3,5$ and 7$)$. For the DEMON algorithm the flow width is a function of aspect

$$
w=|\sin (\theta)|+|\cos (\theta)| .
$$

The flow width for the FD8/FRho8 algorithm is difficult to model well (Quinn, Beven, and Lamb, 1995) and TAPES-G at present uses the D8 flow width; this may change as a result of recent work (Gallant and Hutchinson, 1996).

TAPES-G also computes the rate of change of specific catchment area along the flow path, $\mathrm{d} a / \mathrm{d} s$. This is computed as the specific catchment area of flow leaving the cell less the average of the specific catchment areas entering the cell, divided by the flow length across the cell. This attribute is important in the erosion model used in the EROS program (Wilson and Gallant, 1996a).

\section{Maximum flow path-length}

The maximum flow path-length is the maximum length of all flow paths from the catchment boundary to a given point in the DEM. It can be computed using the D8 or Rho8 algorithms described above, but rather than accumulate areas the algorithm accumulates flow distances across cells, and only the largest flow path-length of all upslope cells is passed on to the downslope cell, instead of the sum. For flow in a cardinal direction ( $i=2,4,6$, or 8 ) the cell flow distance is $h$ (the grid cell spacing), whereas for diagonal flow ( $i=1,3,5$ or 7$)$ the cell flow distance is $\sqrt{2} h$. However, flow paths calculated by these methods tend to have a zig-zag appearance because the flow path directions are restricted to only the eight cardinal directions. Flow paths calculated using the stream tubes constructed by the DEMON algorithm avoid this problem; however the calculation of flow path length using this method has not been implemented in TAPES-G.

\section{APPLICATIONS}

TAPES-G is applied typically to study problems where spatial variation at the topo-scale is important. Topo-scale is the scale at which the landscape is divided into hills and valleys which dominate the spatial patterns of hydrologic response and solar radiation and is associated also with climatic variation hetween the regional scale and the microclimate scale (Linacre, 1992).

A typical application of TAPES-G and its related programs is given in Moore, Norton, and Williams (1993) which describes the analysis and prediction of the spatial variation of Eucalypt species in a mountainous environment. These trees are observed to occupy particular parts of the landscape and the terrain analysis techniques were used to determine which topo-scale variables (short-wave radiation, temperature, relative soil wetness and evaporation) were most important in determining the distribution of each species.

Moore and others (1993b) describes the application of TAPES-G to the study of soil-landscape associations. This study is based on the hypothesis that catenary soil development occurs in response to the 
way water moves through and over the landscape, so the spatial distribution of soil physical and chemical properties should be related to topographic attributes such as slope and specific catchment area. Significant and useful correlations were found between topographic attributes and a number of measured soil attributes, permitting a tentative spatial extrapolation of soil properties from point survey data.

\section{CONCLUSIONS}

TAPES-G is a valuable topographic analysis tool that has been used successfully in a variety of environmental modeling applications, including the modeling of soil-landscape associations and forest ecology. It computes primary topographic attributes which capture the spatial variability of the dominant hydrological processes and serve as inputs to other terrain analysis programs dealing with more physically-based secondary attributes. These primary and secondary topographic indices provide the basic physical parameters for a wide variety of environmental models, and the grid-based methods of terrain analysis discussed in this paper can be expected to provide the primary geographic data for many applications integrating GIS and environmental modeling in the next five to ten years because most of the existing GISs and environmental models are based on a raster (grid cell) data structure.

TAPES-G provides facilities for computing the most important topographic attributes used in hydrological applications, and allows the user to select between the four main algorithms available for calculating contributing area. It provides for analysis of sub-catchments which can be selected interactively using a point-and-click interface, and linkage to the ARC/INFO GIS.

To obtain copies of ANUDEM, TAPES-G and associated programs contact the Centre for Resource and Environmental Studies, Nustralian National University, Canberra ACT 0200, Australia; telephone +6162494277 ; fax +6162490757 . Information is also available via WWW at http://cres.anu.edu.au.

Acknowledgments - This work was funded in part by grant no. ANU3 from the Australian Land and Water Resources Research and Development Corporation, grant nos. SES-8912042 and SES-8912938 from the National Science Foundation, grant no. 2900684 from the United States Department of Agriculture-Cooperative States Research Service, grant no. 101494 from the Montana Agricultural Experiment Station and the M. J. Murdock Charitable Trust. Contribution no. J-3024 of the Montana Agricultural Experiment Station. Most of the code for TAPES-G was written by Professor Ian $D$. Monre before his death in September, 1993 and many of the ideas for integrating GIS and environmental modeling expressed in this paper were developed by him or in collaboration with him. TAPESOUT was prepared by Robert D. Snyder of the Montana State University Geographic Information and Analysis Center.

\section{REFERENCES}

Costa-Cabral, M. C., and Burges, S. J., 1994, Digital elevation model networks (DEMON): a model of flow over hillslopes for computation of contributing and dispersal areas: Water Resources Res., v. 30, no. 6, p. 1681-1692.

Dikau, R., 1989, The application of a digital relief model to landform analysis in geomorphology, in Raper, J., ed., Three Dimensional Applications of Geographic Information Systems: Taylor and Francis, New York, p. $55-77$.

Fairfield, J., and Leymarie, P., 1991, Drainage networks from grid digital elevation models: Water Resources Res., v. 27, no. 5, p. 709-717.

Freeman, T. G., 1991, Calculating catchment area with divergent flow hased on a regular grid: Computers \& Geosciences, v. 17 , no. 3, p. 413-422.

Gallant, J. C., and Hutchinson, M. F., 1996, Specific catchment area and its relationship to plan curvature: Jour. Hydrology (in preparation).

Gallant, J. C., and Wilson, J. P., 1996, WET: A program for estimating soil water and evaporation in complex terrain: Computers \& Geosciences (in preparation).

Grayson, R. B., and Moore, I. D., 1992, Effect of land surface configuration on catchment hydrology, in Parsons, A., and Abrahams, A., eds., Overland Flow: Hydraulics and Erosion Mechanics: Chapman and Hall, New York, p. 393-407.

Holmgren, P., 1994, Multiple flow direction algorithms for runoff modelling in grid based elevation models: an empirical evaluation: Hydrologic Processes, v. 8, p. 327-334.

Hutchinson, M. F., 1989, A new procedure for gridding elevation and stream line data with automatic removal of spurious pits: Jour. Hydrology, v. 106, no. 3-4, p. $211-232$.

Jenson, S. K., and Domingue, J. O., 1988, Extracting topographic structure from digital elevation data for geographic information system analysis: Photogrammetric Enginecring Remote Sensing, v. 54, no. 11, p. $1593-1600$.

Kimerling, A. J., and Moellering, H., 1989, The development of digital slope-aspect displays, in Auto Carto 9: Ninth International Symposium on Computer-Assisted Cartography, April 2-7, 1989, Baltimore, Maryland, p. $241-244$.

Lea, N. J., 1992, An aspect driven kinematic routing algorithm, in Parsons, A., and Abrahams, A., eds., Overland Flow: Hydraulics and Erosion Mechanics: Chapman and Hall, New York, p. 393-407.

Linacre, E., 1992, Climate data and resources: a reference and guide: Routledge, London, $366 \mathrm{p}$.

Mitasova, H., and Hofierka, J., 1993, Interpolation by regularized spline with tension: II. Application to terrain modeling and surface geometry analysis: Math. Geology, v. 25 , no. 6 , p. 657-669.

Moorc, I. D., and Grayson, R. B., 1991, Terrain-based catchment partitioning and runoff prediction using vector elevation data: Water Resources Res, v. 27, no. 6 , p. 1177-1191.

Moore, I. D., and Wilson, J. P., 1992, Length-slope factors for the revised universal soil loss equation: simplified method of estimation: Jour. Soil and Water Conservation, v. 475 , p. $423-428$.

Moore, I. D., Grayson, R. B., and Ladson, A. R., 1991, Digital terrain modelling: a review of hydrological, geomorphological and biological applications: Hydrologic Processes, v. 5, no. 1, p. 3-30.

Moore, I. D., Lewis, A., and Gallant, J. C., 1993, Terrain attributes: estimation methods and scale effects, in Jakeman, A. J., Beck, M. B., and McAleer, M., eds., Modelling Change in Environmental Systems: John Wiley and Sons Ltd, New York, ch. 8. 
Moore, I. D., Norton, T. W., and Williams, J. E., 1993, Modelling environmental heterogeneity in forested landscapes: Jour. Hydrology, v. 150, no. 2-4, p. 717-747.

Moore, 1. D., Gallant, J. C., Guerra, L., and Kalma, J. D., 1993a, Modelling the spatial variability of hydrologic processes using GIS, in Kovar, K., and Nachtenbe, H. P., eds., Application of Geographic Information Systems in Hydrology and Water Resources Management: Proceedings Intern. Conference, Vienna, Austria, April 19-22, 1993, IAHS, Wallingford, variously paged.

Moore, I. D., Gessler, P. E., Nielsen, G. A., and Peterson, G. A., 1993b, Soil attribute prediction using terrain analysis: Soil Science Soc. America Jour., v. 57, no. 2, p. 443-452.

Moore, I. D., Turner, A. K., Wilson, J. P., Jenson, S. K., and Band, L. E., 1993c, GIS and land surface-subsurface process modelling, in ,Goodchild, M. F., Parks, B. O., and Stayaert, L. T., eds., Environmental Modeling with GIS: Oxford University Press, New York, p. 196-230.
O'Callaghan, J. F., and Mark, D. M., 1984, The extraction of drainage networks from digital elevation data: Computer Vision, Graphics and Image Processing, v. 28 , p. 323-344.

Quinn, P., Beven, K., Chevallier, P., and Planchon, O., 1991, The prediction of hillslope flow paths for distributed hydrologic modelling using digital terrain models: Hydrologic Processes, v. 5, p. 59-79.

Quinn, P., Beven, K., and Lamb, R., 1995, The $\ln (a / \tan \beta)$ index: how to calculate it and how to use it within the TOPMODEL framework: Hydrologic Processes, v. 9. p. 161-182.

Wilson, J. P., and Gallant, J. C., 1996a, EROS: A grid-based program for estimating spatially distributederosion indices: Computers \& Geosciences, v. 22, no. 7 . p. $707-712$.

Wilson, J. P., and Gallant, J. C., 1996b, SRAD: A program for estimating radiation and temperature in complex terrain: Computers \& Geosciences (in preparation). 